\title{
Fatores que influenciam o desmame precoce do aleitamento materno: uma revisão integrativa
}

\author{
Factors that influence the early breastfeeding: na integrative review.
}

Factores que influyen en el destelo de la lactancia materna: una revisión integrativa.

Bruna Maciele Pinheiro ${ }^{1 *}$, Rafita Campos Nascimento ${ }^{1}$, Jabneela Vieira Pereira Vetorazo ${ }^{1 .}$

\begin{abstract}
RESUMO
Objetivo: Identificar quais fatores influenciam o desmame precoce do aleitamento materno. Métodos: Trata-se de uma revisão integrativo de literatura, aplicado após combinação de descritores em ciências da saúde nas bases de dados Literatura Latino-Americana e do Caribe em Ciências da Saúde (LILACS), Biblioteca Eletrônica Científica Online (SCIELO) e Biblioteca Virtual em Saúde (BVS) com seleção de 367 artigos e utilização de critérios específicos, foram exclusos 357 artigos e inclusos 10 artigos para análise final. Resultados: Os motivos mais citados pelos autores como sendo de maior importância para a descontinuidade da amamentação exclusiva antes dos seis meses de vida foram: a mãe trabalhar fora de casa, baixo nível de escolaridade das mães, leite fraco, traumas mamilares, uso de bicos artificiais (chupeta e mamadeira) e deficiência na consulta de pré-natal. Considerações finais: Esta pesquisa possibilitou conhecer as diversas causas que podem levar ao desmame precoce. Sugere-se mais estudos sobre essa temática para que haja discussão e elaboração de plano estratégico para prevenção da descontinuidade da amamentação exclusiva antes dos seis meses.
\end{abstract}

Palavras-chave: Fatores de risco, Aleitamento materno, Desmame.

\begin{abstract}
Objective: To identify which factors influence early weaning from breastfeeding. Methods: It is an integrative literature review, applied after combining Health Sciences descriptors in the databases, Latin American and Caribbean Literature in Health Sciences (LILACS), Online Electronic Scientific Library (SCIELO) and Virtual Health Library (VHL) with selection of 367 articles and use of specific criteria, 357 articles were excluded and 10 articles were included for final analysis. Results: The reasons most cited by the authors as being most important for the discontinuation of exclusive breastfeeding before the age of six months were: the mother working outside the home, low level of education of the mothers, weak milk, nipple trauma, use of nipples (pacifier and bottle) and deficiency in prenatal consultation. Final considerations: This research made it possible to know the different causes that can lead to early weaning. Further studies on this topic are suggested so that there is discussion and elaboration of a strategic plan to prevent discontinuity of exclusive breastfeeding before six months.
\end{abstract}

Key words: Risk factors, Breastfeeding, Weaning.

\section{RESUMEN}

Objetivo: Identificar qué factores influyen en el destete de la lactancia materna. Métodos: Es una revisión integrativa de literatura, aplicado tras combinación de descriptores em ciencias de la salud en las bases des datos, Literatura Latinoamericana Y Caribeña En Ciencias De La Salud (LILACS), Online Biblioteca Científica Electrónica (SCIELO) y Biblioteca Virtual en Salud (BVS) con selección de 367 artículos y utilización de criterios específicos, se han excluido 357 artículos e incluidos 10 artículos para análisis final. Resultados: Los motivos más citados por los autores siendo de mayor importancia para la discontinuidad de la lactancia materna exclusiva antes de los seis meses de vida fueron: la madre trabajar fuera de casa, bajo nivel de escolaridad de las madres, leche débil, traumas mamilares, uso de boquillas artificiales (chupete y biberón) y deficiencia en la consulta prenatal. Consideraciones finales: Esta investigación permitió conocer las diversas causas que pueden llevar al destete precoz. Se sugieren más estudios sobre esa temática, para que haya discusión y elaboración de un plan estratégico para prevenir discontinuidad de la lactancia materna exclusiva antes de los seis meses.

Palabras clave: Factores de riesgo, Lactancia materna, Destete.

${ }^{1}$ Centro Universitário Aparício Carvalho (FIMCA), Porto Velho - RO. *E-mail: brunamaciele20@hotmail.com 


\section{INTRODUÇÃO}

Segundo o Ministério da Saúde (MS), amamentar não é somente alimentar o lactante, é uma oportunidade de criar relação binômia (mãe/filho) que tem um impacto importante na nutrição da mesma, de suma importância para defesa contra infecções, sob sua fisiologia, desenvolvimento intelectual e emocional, além do impacto na saúde física e psicológica da puérpera (BRASIL, 2009). A amamentação não é completamente instintiva, ela precisa ser aprendida para que possa ser realizado com exatidão (ARAÚJO OD, 2008).

Existem cinco tipos de aleitamento materno, eles são: aleitamento materno exclusivo, consiste na criança se alimentar somente com o leite materno, não recebendo nenhum outro alimento ou líquido, exceto medicamento, quando necessário; aleitamento materno predominante, no qual há introdução de líquidos; aleitamento materno, leite diretamente da mama; aleitamento materno complementado, além de leite materno, recebe alimentos semissólidos ou sólidos como forma complementar e aleitamento materno misto ou parcial, além de leite materno há ingestão de outros leites (BRASIL, 2015).

Nos primeiros seis meses são recomendados o aleitamento materno exclusivo e os outros tipos de aleitamentos após seis meses, pois antes desse período pode interferir no crescimento saudável do lactante, além de influenciar no tempo da amamentação e hábitos alimentares. A criança deve ser amamentada até os dois anos de vida e os alimentos após os seis meses são complementares e não devem substituir a amamentação (CARVALHO JL, et al., 2016).

Essa prática deve ser incentivada e preservada, pois se constitui um método de promoção de saúde que beneficia a criança e a mãe. Porém, mesmo que se tenham pesquisas cientifica que revela à eficácia do leite materno em relação aos outros leites, ainda sim, a taxa de amamentação é menor que o recomendado pelas instituições de saúde nacionais e internacionais. Nesse processo não basta ter apenas habilidades técnicas, mas deve-se ter uma visão holística para avaliar a individualidade de cada puérpera, como fatores culturais, emocionais, economia, entre outros (LIMA SP, 2019). O enfermeiro tem importante participação na promoção da amamentação e deve estar habilitado, visto que assiste as mães no pré-natal e nos dois primeiros anos de vida da criança e está continuamente em contato com elas na comunidade, o que ajuda e viabiliza a promoção do aleitamento materno de maneira intensificada e eficaz com vistas à redução de desmame precoce (ALVES EA, 2010).

O desmame precoce é quando há ingestão de outros líquidos e alimentos antes do lactente haver completado seis meses, independentemente de a decisão ser materna ou não e do motivo de tal interrupção (CABRAL VL e CAMPESTRINI S, 2010). O aleitamento materno é de suma importância para combater a fome extrema e impedir que crianças desenvolvam desnutrição, principalmente nos dois primeiros anos de vida, sendo ele o responsável pela diminuição da taxa de mortalidade infantil. Porém, apesar dos inúmeros benefícios que são comprovados cientificamente, ainda se tem um alto índice de desmame precoce (OLIVEIRA CS, 2015).

Diante do exposto, a presente pesquisa teve como finalidade identificar quais os fatores que influenciam o desmame precoce do aleitamento materno.

\section{MÉTODOS}

Trata-se de uma revisão integrativa da literatura, acerca dos fatores que estão relacionados ao desmame precoce do aleitamento materno, de caráter descritivo e abordagem qualitativa. Segundo Mattos PC (2015), revisão integrativa é um tipo revisão de literatura, surgiu como metodologia alternativa de revisão rigorosa de combinações de várias pesquisas (experimental e não experimental) analisando e integrando os dados. É possível realizar pesquisas de revisão em várias áreas de aprendizado e manter o critério da metodologia de revisão sistemática.

Essa metodologia ajuda na construção da visão holística sobre as necessidades diárias relacionada a temática. Para a realização desse método são utilizadas seis fases: elaboração da pergunta que irá nortear o estudo, pesquisa nas bases de dados, coleta dos dados, análise minuciosa das pesquisas selecionadas, discussão dos resultados encontrados e apresentação da revisão integrativa (SOUSA MT, et al., 2010). 
Desse modo, a pesquisa teve como pergunta norteadora: "Quais fatores influenciam o desmame precoce do aleitamento materno?". A revisão de literatura foi realizada no mês de janeiro de 2021, para localização dos estudos foi realizado consulta aos Descritores em Ciências da Saúde (DECS) estes foram convencionados com o operador booleano "AND": "Aleitamento materno AND fatores de risco AND desmame" e "Aleitamento materno AND desmame"

. A procura das obras científicas foi realizada através das plataformas eletrônicas: Literatura LatinoAmericana e do Caribe em Ciências da Saúde (LILACS), Biblioteca Eletrônica Científica Online (SCIELO) e Biblioteca Virtual em Saúde Brasil (BVS).

Realizou-se a leitura do título e resumo dos artigos para que fossem selecionados aqueles que seriam inclusos e exclusos. Os artigos incluídos foram os que abordavam conteúdo que atingisse o objetivo da pesquisa, publicados no período de 2016 a 2020, texto completo e artigos em português. Os excluídos foram aqueles que não respondiam à pergunta do estudo, artigos sem traduções em português e artigos duplicados.

Posteriormente a aplicação dos critérios, os artigos selecionados foram lidos na íntegra com a finalidade de inclui-los ou não na pesquisa. Para avaliação foi utilizado o programa Excel para tabulação dos dados, os mesmos foram organizados para melhor compreensão dos resultados. O quadro foi proposto por Souza MT, et al. (2010), e as pesquisadoras adaptaram para o estudo.

\section{RESULTADOS}

Através das buscas nas bases de dados, foram encontrados 367 artigos, após a aplicação dos critérios foram excluídos 328, pois não correspondiam ao objetivo da pesquisa, 20 artigos por duplicidades, 04 artigos em inglês e 5 artigos em espanhol sem tradução para o português.

Após a leitura dos títulos e resumos, 16 artigos foram selecionados para leitura na íntegra, posteriormente a leitura, 6 artigos foram excluídos, o que possibilitou ao final, inclusão de 10 artigos para serem analisados com a finalidade de subsidiar a revisão de literatura (Figura 1). As plataformas que proporcionaram maior volume de obras foram: LILACS ( 5 artigos, 5,37\%); BVS (3 artigos, 1,58\%) e SCIELO (2 artigos, 2,35\%). Anos de publicação, 2016 (0\%), 2017 (40\%), 2018 (50\%), 2019 (10\%) e 2020 (0\%). Dos artigos que foram incluídos na revisão, todos foram publicados no idioma português (100\%).

Figura 1 - Fluxograma da seleção dos artigos para esta revisão integrativa.

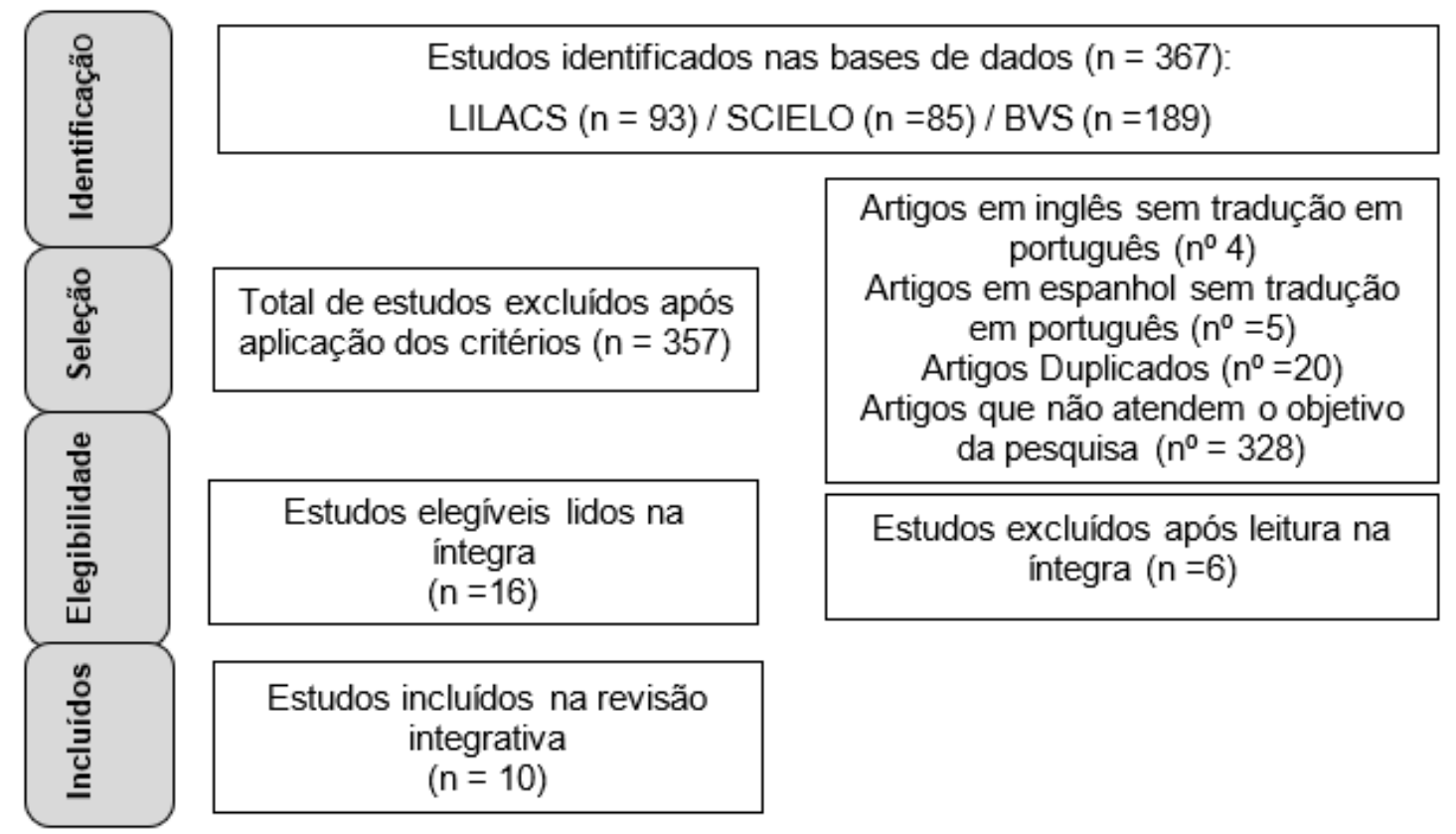

Fonte: Pinheiro BM, et al., 2021. 
Quanto ao tipo de estudo, identificou-se pesquisas de revisão Integrativa (20\%), estudo descritivo com abordagem qualitativa e exploratória (20\%), descritivo com abordagem qualitativo (10\%), revisão sistemática (10\%), estudo prospectivo observacional e analítico (10\%), estudo transversal com abordagem descritiva (10\%), estudo exploratório descritivo de abordagem quantitativa (10\%), estudo observatório quantitativo e campo (10\%). No Quadro 1, consta o total de artigos encontrados após aplicação dos descritores com os filtros de inclusão e exclusão definidos.

Quadro 1 - Estudos utilizados na pesquisa conforme: base de dados, autores, tipo de estudo e resultados mais relevantes.

\begin{tabular}{|c|c|c|c|}
\hline Base de dados & Autores & Tipo de estudo & Resultados mais relevantes \\
\hline $\begin{array}{l}\text { Scientific Electronic } \\
\text { Library online } \\
\text { (SCIELO) }\end{array}$ & $\begin{array}{l}\text { OLIVEIRA AK, et al., } \\
2017 .\end{array}$ & $\begin{array}{l}\text { Estudo descritivo, de } \\
\text { abordagem qualitativa. }\end{array}$ & $\begin{array}{l}\text { Os fatores que influenciam no desmame } \\
\text { precoce: voltar ao trabalho, dificuldade da } \\
\text { criança em pegar a mama, introdução de } \\
\text { outros alimentos, estética da mama, práticas } \\
\text { e crenças populares influenciadas pelo } \\
\text { convívio social e familiar, deficiência na } \\
\text { consulta de pré-natal, quanto à orientação do } \\
\text { aleitamento materno exclusivo. }\end{array}$ \\
\hline $\begin{array}{l}\text { Scientific Electronic } \\
\text { Library online } \\
\text { (SCIELO) }\end{array}$ & $\begin{array}{l}\text { ALVARENGA SC, et } \\
\text { al., } 2017 .\end{array}$ & Revisão sistemática & $\begin{array}{l}\text { Os fatores mais apontados nesse estudo } \\
\text { foram: trabalho materno, uso de chupeta, } \\
\text { leite fraco, trauma e dor mamilar, introdução } \\
\text { de outros tipos de leites e escolaridade da } \\
\text { mãe/pai. }\end{array}$ \\
\hline $\begin{array}{l}\text { Literatura Latino- } \\
\text { Americana e do } \\
\text { Caribe em Ciências } \\
\text { da Saúde (LILACS) }\end{array}$ & $\begin{array}{c}\text { BARBOSA GEF, et al., } \\
2018 .\end{array}$ & $\begin{array}{l}\text { Estudo prospectivo, } \\
\text { observacional e } \\
\text { analítico. }\end{array}$ & $\begin{array}{l}\text { Fatores associados à interrupção do } \\
\text { aleitamento materno: problemas com as } \\
\text { mamas, trabalho materno fora de casa, baixo } \\
\text { nível de escolaridade materna. }\end{array}$ \\
\hline $\begin{array}{l}\text { Literatura Latino- } \\
\text { Americana e do } \\
\text { Caribe em Ciências } \\
\text { da Saúde (LILACS) } \\
\end{array}$ & NERI VF, et al., 2019. & $\begin{array}{l}\text { Estudo transversal } \\
\text { descritivo }\end{array}$ & $\begin{array}{l}\text { Fatores relacionados ao desmame precoce: } \\
\text { idade entre } 20-30 \text { anos, baixa escolaridade, } \\
\text { mães empregadas, mulheres casadas e leite } \\
\text { fraco. }\end{array}$ \\
\hline $\begin{array}{l}\text { Literatura Latino- } \\
\text { Americana e do } \\
\text { Caribe em Ciências } \\
\text { da Saúde (LILACS) }\end{array}$ & $\begin{array}{l}\text { ANDRADE HS, et al., } \\
2018 .\end{array}$ & $\begin{array}{l}\text { Pesquisa de cunho } \\
\text { exploratório, descritiva } \\
\text { de abordagem } \\
\text { quantitativa. }\end{array}$ & $\begin{array}{l}\text { Fatores apontados que levam ao desmame } \\
\text { precoce: idade materna (jovem), baixo nível } \\
\text { de escolaridade, baixa renda familiar, } \\
\text { trabalho materno, primípara, gravidez não } \\
\text { planejada, leite fraco ou insuficiente, bebê } \\
\text { chorar e não pegar a mama. }\end{array}$ \\
\hline $\begin{array}{l}\text { Literatura Latino- } \\
\text { Americana e do } \\
\text { Caribe em Ciências } \\
\text { da Saúde (LILACS) }\end{array}$ & LIMA SP, et al., 2018. & $\begin{array}{l}\text { Revisão integrativa da } \\
\text { literatura }\end{array}$ & $\begin{array}{l}\text { Fatores causadores do desmame precoce: } \\
\text { leite fraco, trabalho materno, baixo nível de } \\
\text { escolaridade, idade materna, primigestas, } \\
\text { uso de bicos artificiais, traumas mamilares e } \\
\text { deficiência de dos profissionais de saúde na } \\
\text { hora de passar informação. }\end{array}$ \\
\hline $\begin{array}{l}\text { Literatura Latino- } \\
\text { Americana e do } \\
\text { Caribe em Ciências } \\
\text { da Saúde (LILACS) }\end{array}$ & $\begin{array}{l}\text { BATISTA CLC, et al., } \\
2017 .\end{array}$ & $\begin{array}{l}\text { Revisão integrativa da } \\
\text { literatura }\end{array}$ & $\begin{array}{l}\text { Fatores associados ao desmame precoce: } \\
\text { uso de bicos artificias, trabalhar fora de casa } \\
\text { e problemas mamários. }\end{array}$ \\
\hline $\begin{array}{c}\text { BVS Biblioteca } \\
\text { Virtual em Saúde } \\
\text { Brasil } \\
\end{array}$ & $\begin{array}{c}\text { SANTOS PV, et al., } \\
2018 .\end{array}$ & $\begin{array}{l}\text { Estudo descritivo, } \\
\text { quantitativo e } \\
\text { exploratório. } \\
\end{array}$ & $\begin{array}{l}\text { Fatores apontados que levam ao desmame } \\
\text { precoce: influência da família, amigos ou } \\
\text { outras pessoas e trabalho materno. }\end{array}$ \\
\hline $\begin{array}{l}\text { BVS Biblioteca } \\
\text { Virtual em Saúde } \\
\text { Brasil }\end{array}$ & $\begin{array}{l}\text { EUSEBIO BL, et al., } \\
2017 .\end{array}$ & $\begin{array}{l}\text { Pesquisa } \\
\text { qualitativa do tipo } \\
\text { exploratória descritiva }\end{array}$ & $\begin{array}{l}\text { Fatores que contribuem para o desmame } \\
\text { precoce: traumas mamilares, voltar ao } \\
\text { trabalho e falta de orientação do profissional } \\
\text { de saúde. }\end{array}$ \\
\hline $\begin{array}{c}\text { BVS Biblioteca } \\
\text { Virtual em Saúde } \\
\text { Brasil } \\
\end{array}$ & $\begin{array}{l}\text { FREITAS MG, et al., } \\
2018 .\end{array}$ & $\begin{array}{l}\text { Estudo observacional, } \\
\text { quantitativo e de campo. }\end{array}$ & Principal fator apontado: leite insuficiente. \\
\hline
\end{tabular}

Fonte: Pinheiro BM, et al., 2021.

Após a leitura aprofundada das pesquisas selecionadas, foi possível identificar os motivos mais citado pelos autores como sendo de maior relevância para descontinuidade da amamentação exclusiva, eles são: 
trabalho materno; baixo nível de escolaridade da mãe; leite fraco; traumas mamilares; uso de bicos artificiais (chupetas e mamadeiras) e deficiência na consulta de pré-natal.

Outros fatores citados que também influenciam no desmame precoce são: dificuldade do lactante em pegar a mama, introdução de outros alimentos/leites, prática e crenças populares, idade materna, primípara, estética da mama, estado civil, baixa renda familiar e gravidez não planejada.

\section{DISCUSSÃO}

O fator mais citado como influenciador na descontinuidade da amamentação exclusiva nos primeiros seis meses foi à mãe trabalhar fora de casa. Alvarenga SC, et al. (2017), traz em sua pesquisa que as mulheres trabalham fora para poderem ajudar nas despesas ou porque assumem papel de chefe da família, e, por necessidade de manter o lar, elas acabam deixando de amamentar seus bebês de forma exclusiva até os seis meses.

Barbosa GEF, et al. (2018) e Lima SP, et al. (2018), apontam que as mulheres que desenvolvem atividades externas de sua residência têm menos contato com seus filhos e ver premência de introdução de outros alimentos.

Alvarenga SC, et al. (2017) e Andrade HS e Donizete LC (2018), destacam a lei ํo 5.452 que refere-se ao direito de licença maternidade, pois, ainda que as mulheres tenham política de amparo, frequentemente 0 local de trabalho não dispõem de ambiente adequado para que as puérperas amamentem ou façam ordenha, dificultando a amamentação exclusiva.

Porém em um estudo desenvolvido por Santos PV, et al. (2018), houve desmame precoce tanto em puérperas que tiveram licença maternidade quanto nas que não tiveram, não corroborando com os autores acima citados. Diante do exposto, verifica-se a necessidade dessas mulheres receberem informações claras sobre amamentação para que possam juntamente com sua família elaborar um planejamento para que consigam manter o aleitamento materno exclusivo. Destacamos ainda a importância de elaboração de outros estudos para que exista maior sustentação em intervenções frente a essa problemática.

Outro fator citado foi o baixo nível de escolaridade da mãe, segundo os autores Barbosa GE, et al. (2018) e Lima AP (2018), mães que possuem baixo nível de escolaridade tendem a interromper a amamentação exclusiva e ficam vulneráveis ao desmame precoce por serem influenciadas por familiares, amigos ou vizinhos.

Isso pode ser confirmado no estudo desenvolvido por Oliveira AK, et al. (2017), aponta que as puérperas se sentem inseguras em cuidar ou amamentar seus filhos, elas tendem a confiar em pessoas próximas que tiveram alguma experiência, essas vivências passadas de geração em geração nem sempre condizem com o recomendado pelos profissionais de saúde e levam a oferta de outros alimentos antes da criança completar seis meses. Destacou ainda alguns fatores que foram relatados pelas mães como justificativa para o desmame precoce: leite fraco; a criança sentir sede, então é ofertado sucos, chás, água; amamentar por muito tempo muda a estética da mama e dificuldade do lactante em pegar mama. Tudo isso leva também a introdução de bicos artificiais (chupeta e mamadeiras).

Andrade HS, et al. (2018), afirmam que as puérperas acreditam que o leite seja fraco devido, no início, o leite se apresentar transparente, então elas concluem que não é suficiente para sustentar a criança. Além disso, pode estar associado ao pouco ou nenhum conhecimento sobre as características do leite ou fator cultural. Apontou ainda que muitas mães não se sentem seguras para amamentar e usam essa justificativa para desmamar precocemente o lactante.

Freitas MG, et al. (2018) e Alvarenga SC, et al. (2017), também relatam que os motivos que levam as mães acreditarem que o leite é fraco está relacionado com a insegurança da mesma em amamentar e que isso é reforçada muitas vezes por pessoas próximas.

Segundo Lima AP, et al. (2018), a chupeta frequentemente é usada para acalmar o bebê, principalmente na ausência da figura materna. Batista CL, et al. (2017), relata que o uso desses bicos artificiais vem para satisfazer a vontade de sucção do lactante e essa influência vem de práticas e crenças culturais. 
É possível analisar que a baixa escolaridade materna pode associar-se as crenças e práticas populares e formarem um grande potencial para ingestão de outros alimentos antes dos seis meses de vida. Porém o estudo desenvolvido por Santos PV, et al. (2018), não corroborou com Barbosa GE, et al. (2018) e Lima AP, et al. (2018), pois apontou que a maioria das puérperas que participaram da pesquisa estudaram menos de 11 anos e não influenciou no desmame precoce.

Referente a traumas mamilares, Alvarenga SC, et al. (2017), relata que o pouco conhecimento das puérperas acerca do aleitamento materno faz com que elas não amamentem com a técnica correta, gerando dor e trauma mamilar, a mesma começa ficar com receio de amamentar e isso interfere no reflexo de ejeção do leite materno e a criança não consegue ter a mamada adequada, estimulando assim, o desmame precoce.

Euzébio BL, et al. (2017), corrobora com o resultado acima, mostrou que as principais queixas eram referentes a dor na mama, fissuras, dificuldade de o bebê abocanhar a aréola, gerando assim uma pressão psicológica nas mães e desmotivando a amamentação exclusiva.

Lima AP, et al. (2018), também aponta o trauma mamilar como um fator que pode ocasionar a descontinuidade da amamentação exclusiva, destacando ainda a mastite como um problema comum no início do aleitamento materno.

Porém, segundo Barbosa GE, et al. (2018), técnica das mamadas, posição da puérpera e do lactante e problemas com a pega da mama não se mostraram significativos para a descontinuidade da amamentação exclusiva, mas destacou que esse resultado pode estar relacionado ao fato da pesquisa ser desenvolvida em Hospital Amigo da Criança.

A Iniciativa Hospital Amigo da Criança foi criada em 1990 para incentivar, ensinar a técnica correta do aleitamento materno e que houvesse diminuição de mortalidade infantil e melhora na qualidade de vida tanto da criança como da puérpera. Essa iniciativa foi em parceria com a Organização Mundial da Saúde e Fundo das Nações Unidas para a Infância (UNICEF) em resposta a ação de Declaração de Innocenti, passou a ser implementado em 1992 fazendo parte da ação do Programa Nacional de Incentivo ao Aleitamento Materno (PNIAM) BRASIL, 2010).

Neri VF, et al. (2019), identificou que, a prevalência da descontinuidade da amamentação exclusiva foi em uma faixa etária entre 20 a 30 anos, sendo essa, biologicamente congruente para a gestação, porém é também um período que pode trazer diversas dificuldades para a puérpera, como conseguir um emprego, estudos e outros motivos sociais que podem influenciar negativamente na amamentação. Andrade HS, et al. (2018), elaborou estudo com mulheres entre 18 a 23 anos e concluiu que o fato dessas mães serem menos experientes, possuem mais dúvidas e anseios relacionados a amamentação, onde há certa tendência a desmamar precocemente seus bebês.

Andrade HS, et al. (2018), trouxeram em sua pesquisa que mães de apenas um filho teve importância no desmame precoce, onde associam isso ao fato de serem inexperiente em cuidados e amamentação do lactante. Também relata que mães que não planejaram a gravidez estão vulneráveis a introduzir outros alimentos antes dos seis meses, pois elas não se sentem preparadas para cuidar e amamentar, destacando a relevância do profissional de saúde ter uma visão holística para essa situação, o mesmo deve incentivar e passar todas as informações necessárias para um bom aleitamento materno.

Já Santos PV, et al. (2018), apontou que a maior parte das mães que participaram do seu estudo tinham mais de um filho e a metade delas realizaram desmame precoce.

Referente a deficiência na consulta de pré-natal, Oliveira AK, et al. (2017), relatou que apesar da importância da orientação profissional durante o pré-natal, evidenciou-se um grande número de gestantes que não recebeu nenhum tipo de orientação na consulta, e as que receberam, reportaram a figura do enfermeiro como o único profissional que trouxe esclarecimentos e orientações dentro desse contexto da amamentação.

Euzébio BL, et al. (2017), também destacou que grande parte das puérperas não receberam orientações sobre amamentação, quando receberam, foi principalmente no pós-parto onde já estavam apresentando dificuldades e as informações foram realizadas pelos profissionais da enfermagem. 
O enfermeiro tem um destaque especial, pois atua como facilitador e encorajador do aprendizado sobre amamentação, além de atuar no esclarecimento de dúvidas. É necessária uma comunicação simples e objetiva durante a orientação, incentivo e ajuda na amamentação e demonstração dos tipos de posições para realizar o aleitamento materno (AMORIM MM e ANDRADE HS, 2009).

Porém, segundo os autores Oliveira AK, et al. (2017) e Neri VF, et al. (2019), relatam em seus estudos que um grande número de puérperas recebeu orientações nas consultas e sabiam da relevância da amamentação, porém a maioria realizou o desmame precoce. Barbosa GE, et al. (2018), Também relata em sua pesquisa que as mulheres receberem orientações nas consultas de pré-natal e não teve relevância no tempo da amamentação.

O enfermeiro foi destacado pelas mães como o profissional que mais orienta sobre amamentação, mostrando o seu papel fundamental frente ao aleitamento materno. Foi possível analisar que além da orientação do profissional da saúde, também é importante que as puérperas estejam dispostas a realizar o aleitamento materno exclusivo, pois sem esse interesse, por mais que se tenha orientação, irá ocorrer o desmame precoce.

Neri VF, et al. (2019), apontaram que a maior parte das mulheres que participaram da pesquisa eram casadas e realizaram a descontinuidade da amamentação precocemente. Santos PV, et al. (2018), corroborou com o autor acima, mas destacou que as quais não tinham companheiro também não realizaram a amamentação exclusiva até os seis meses.

Segundo Andrade HS, et al. (2018), o fato de mulheres casadas realizarem a descontinuidade da amamentação precocemente pode estar relacionado com a sobrecarga de trabalho doméstico, deixando de amamentar como deveria.

É importante que o companheiro ou familiares ajudem as puérperas para que elas possam amamentar por livre demanda (quando o lactante quiser) e consigam manter a amamentação exclusiva, ajudando também a diminuir o estresse, ansiedade e frustações, pois a chegada de uma criança causa mudanças no ambiente familiar e nesse momento é significativo que a mãe também seja assistida.

Andrade HS, et al. (2018), apontam que puérperas de menor renda costumam desmamar precocemente, pois a procura pelos atendimentos de saúde é baixa. Porém para Barbosa GE, et al. (2018) e Neri VE, et al. (2019), esse fator atuou como protetor para amamentação exclusiva. Eusébio BL, et al. (2017), relatou em seu estudo que mulheres de classe econômica mais alta foram as que mais realizaram desmame precoce.

Um dos fatores que chamou atenção nesta pesquisa foi a renda familiar, pois alguns autores relatam que a baixa renda familiar é um fator de risco e outros relatam que é um fator protetor. Acredita-se que a baixa renda pode interferir na amamentação exclusiva, pois as mães precisam trabalhar para sustentar a família, fazendo assim, que elas precisem introduzir outros alimentos antes dos seis meses. Já quando é apontado que essa mesma classe foi um motivo protetor para o aleitamento materno exclusivo, pode-se associar ao alto custo dos leites e alimentos, sendo mais viável alimentar a criança somente na mama.

\section{CONSIDERAÇÕES FINAIS}

Os motivos mais citados pelos autores como sendo de maior relevância para a descontinuidade da amamentação exclusiva foram, puérperas trabalharem fora de casa, baixo nível de escolaridade da mãe, leite fraco, traumas mamilares, uso de bicos artificiais e deficiência na consulta de pré-natal. Dessa maneira, sugere-se mais estudos sobre fatores que interferem na amamentação exclusiva para que assim haja uma maior discussão desses e também elaboração de estratégias onde os mesmos sejam prevenidos.

\section{REFERÊNCIAS}

1. ALVARENGA SC, et al. Fatores que influenciam o desmame precoce. AQUICHAN- Revista Cientifica de la Facultad de Emfermería y Rehabilitación, 2017; 17(1): 93-103. 
2. ALVES EA. Fatores determinantes do desmame precoce. Minas Gerais. Monografia (Especialização) Especialização em Atenção Básica em Saúde da Família, Núcleo de Educação em Saúde Coletiva da Universidade Federal de Minas Gerais, Minas Gerais. 2010: 46 p.

3. AMORIM MM, ANDRADE ER. Atuação do enfermeiro PSF sobre aleitamento materno. Revista Científica Perspectivas online, 2009; 3(9): $93 \mathrm{p}$.

4. ANDRADE HS, et al. Fatores relacionados ao desmame precoce do aleitamento. Revista Brasileira de Medicina de Família e Comunidade, 2018; 13(40): 1-11.

5. ARAÚJO OD, et al. Aleitamento materno: fatores que levam ao desmame precoce. Revista Brasileira de Enfermagem, 2008; 61(4): 448-492.

6. BARBOSA GEF et al. Dificuldades iniciais com a técnica da mamada e impacto na duração do aleitamento materno exclusivo. Revista Brasileira de saúde Materno Infantil, 2018; 18(3): 527-537.

7. BATISTA CLC, et al. Influência do uso de chupetas e mamadeiras na prática do aleitamento materno. Journal of Health \& Biological Sciences Revista de Saúde e Ciências Biológicas, 2017; 5(2): 184-191.

8. BRASIL. Ministério da Saúde. Área Técnica de Saúde da Criança e Aleitamento Materno. Departamento de Ações Programáticas Estratégicas. Secretária de Atenção à Saúde. Iniciativa Hospital Amigo da Criança. Brasília, 2010.

9. BRASIL. Ministério da Saúde. Secretaria de Atenção à Saúde. Departamento de Atenção Básica. Saúde da criança: nutrição infantil: aleitamento materno e alimentação complementar/Ministério da Saúde. Brasília, 2015.

10. CABRAL VLM, CAMPESTRINI S. Programa de aleitamento materno - Palma. Pontifícia Universidade Católica do Paraná. Mães desejosas de amamentar enfrentam despreparo profissional.

11. CARVALHO JLS, et al. Conhecimento das mães sobre aleitamento materno exclusivo e amamentação complementar. Saúde em Redes, 2016; 2(4): 383-392.

12. ELZÉBIO BL, et al. Amamentação: Dificuldades encontradas pelas mães que contribuem para o desmame precoce. O Boletim da Saúde, 2017; 26(2): 83-89.

13. FREITAS MG, et al. Aleitamento materno exclusivo: adesão e dificuldades. Revista de Enfermagem Universidade Federal de Pernambuco online, 2018; 12(9): 2301-2307.

14. LIMA AP, et al. A prática do aleitamento materno e os fatores que levam ao desmame precoce: uma revisão integrativa. Journal of Health \& Biological Sciences Revista de Saúde e Ciências Biológicas, 2018; 6(2): 189-196.

15. LIMA SP, et al. Percepção de mulheres quanto á pratica do aleitamento materno: uma revisão integrativa. Revista Online de Pesquisa, 2019; 11(1): 248-254.

16. MATTOS PC, Tipos de Revisão de Literatura. Faculdades de Ciências Agrônomas - Universidade Estadual Paulista, Campos Botucatu. São Paulo, 2015.

17. MONTEIRO JCS, O aleitamento materno enquanto uma prática construída: reflexões acerca da evolução histórica da amamentação e desmame precoce no Brasil.Investigación y Educación en Enfermería, 2011; 29(2): 315-322.

18. NERI VF, et al. Prevalência de desmame precoce e fatores relacionados em crianças do Distrito Federal e entorno. REVISA, 2019; 8(4): 451-459.

19. OLIVEIRA AK, et al. Práticas e crenças populares associadas ao desmame precoce. Avances em Enfermagem, 2017; 35(3): 303-312.

20. OLIVEIRA CS, et al. Amamentação e as intercorrências que contribuem para o desmame precoce. Revista Gaúcha de Enfermagem, 2015; 1(36): 16-23.

21. SANTOS PV, et al. Desmame precoce em crianças atendidas na Estratégia de Saúde da Família. Revista Eletrônica de Enfermagem, 2018; 20(20):1-12.

22. SILVEIRA FJ, LAMOUNIER JA. Fatores associados à duração do aleitamento materno em três municípios na região do Alto Jequitinhonha, Minas Gerais, Brasil. Caderno de Saúde Pública 2006; 22(1): 69-77.

23. SOUZA MT, Revisão integrativa: o que é e como fazer. Einstein, 2010; 8(1): 102-106. 